\title{
ARTIGOS
}

\section{O IMPÉRIO ROMANO EM ATENAS: INTEGRAÇÃO E INTERVENÇÃO IMPERIAL NO SÉCULO II D.C.}

\author{
Carlos Augusto Ribeiro Machado*
}

\begin{abstract}
Resumo
Este artigo procura analisar as relações políticas estabelecidas entre o Império Romano e as cidades gregas no séc. II. A manutenção do Império após a conquista pela força militar exigiu recursos sofisticados, como por exemplo, o envio de embaixadas urbanas para defender seus interesses junto ao imperador.

Palavras-chave: Império Romano; Marco Aurélio; cidades gregas.

Existe uma extensa bibliografia sobre as relações entre o poder imperial romano e as cidades gregas do alto Império (por exemplo, Millar, $1983 ; 1984 ; 1992)$. Obviamente isso não esvazia o tema de interesse. Afinal, além de ser bem documentado, permite colocar questões teoricamente relevantes: como a estrutura de poder imperial se fazia presente localmente? Qual o tipo de relação existente entre poder central e comunidade local? Ou então, de forma mais concreta, como funcionava e quais eram os limites da organização política que chamamos Império Romano? O interesse desse tipo de questão reside na possibilidade de rediscutirmos a observação de Ernest Gellner (1981, p. 43) a respeito dos impérios na antigüidade:
\end{abstract}

\footnotetext{
• Doutorando em História Econômica - FFLCH/USP.
} 
Em conjunto, as unidades que os compunham poderiam sobreviver tão bem,ou quase, ou até melhor, se a totalidade tivesse permanecido fragmentada. Mas, grosso modo, é o império que requer explicação, e não o seu colapso, ou a persistência da fragmentação.

A leitura de uma inscrição encontrada na Ágora romana de Atenas em 1966 (Oliver, 1970, prancha 2) ${ }^{1}$, na qual o imperador Marco Aurélio responde a apelações feitas por cidadãos atenienses nos permite recolocar estas questões, ainda que de forma limitada.

Procurando definir as relações Imperadores-cidades gregas, os historiadores salientaram diversos aspectos. Alguns, como Peter Garnsey e Richard Saller (1987, p. 26), observaram que as cidades (inclusive a Grécia) eram um importante elemento do governo imperial, ao mesmo tempo em que enfatizaram a unidade do Império como um todo. Isso não impediu que outros estudiosos vissem nas cidades gregas um caso à parte, devido ao reduzido impacto que a dominação romana teve sobre aquela civilização (p.ex. Jones, 1984, p. 119 e Millar, 1976). Isso não significa que estejamos tratando de visões incompatíveis, no entanto: se é verdade que o Império pode ser visto como um produto do crescente grau de coesão entre as elites provinciais e romanas, é necessário admitir que essa coesão foi construída de acordo com padrões distintos, variando conforme a época e a região.

Podemos partir do princípio de que o Império era concretizado regionalmente na forma de uma rede de cidades, especialmente no Leste. Aí, onde a vida urbana era um fenômeno mais comum do que no Ocidente antes mesmo da chegada das tropas conquistadoras, encontramos um quadro extremamente diversificado. As cidades apresentavam uma grande diversidade de status, possuindo as mais díspares constituições. O fato de Roma ter favorecido, desde a República, o domínio das oligarquias municipais não obscureceu essa característica da vida cívica helenística. Mais interessante do que isso, aliás, é observar que praticamente nenhum imperador chegou a perseguir uma política uniformizadora, imposta de "cima" para "baixo". Como observou Fergus Millar, o Imperador governava de acordo com um princípio que podemos chamar de "petição-resposta", ou seja: longe de formular políticas gerais, agia de acordo com a pressão dos súditos. Ouvindo petições e apelos, lendo cartas e relatórios, um imperador como Marco Aurélio (que reinou 
de 161 a 183 d.C.) podia entrar em contato com as populações dominadas, fazendo-se presente com suas decisões, que podiam ou não atendê-las. Apesar de não concordarmos com a idéia de que o imperador se limitava a esse papel (Millar (1992, p. 6) define: "The emperor was what the emperor did."), essa era uma dimensão importante de suas atividades e é justamente esse elemento que iremos explorar daqui em diante.

Devido à importância deste aspecto da relação entre o poder imperial e a população do Império, devemos ressaltar o problema colocado pelas dificuldades existentes em sua aplicação: se o Imperador não podia estar em todos os lugares, e muitas vezes o que estava em questão era justamente uma apelação de uma decisão de seus representantes, como seria possível entrar em contato com ele? Desde o início do Império, as cidades adotaram a prática de enviar embaixadas a Roma, à corte ou aonde quer que o endereçado estivesse (às vezes em campanhas militares). Estas embaixadas podiam envolver um ou mais homens, geralmente dotados de bons contatos na corte, educados o suficiente para apresentar os casos de uma maneira favorável ou convincente ao detentor do trono. Por isso, buscavam os membros mais cultos de suas cidades, treinados na arte da retórica, para servirem de representantes. Embaixadas eram enviadas por motivos diversos, pedindo isenções de impostos, oferecendo templos e cultos à família imperial, e até mesmo apresentando questões jurídicas.

Cabia ao imperador ouvir cada uma das embaixadas, tomar decisões e, conforme o caso, divulgá-las. Não é de surpreender que essa atividade tomasse um grande tempo, mesmo durante campanhas. Ao narrar a passagem de Marco Aurélio pela região do Danúbio por volta de 174, Dião Cássio observou que:

O imperador, sempre que tinha folga da guerra, realizava audiências; costumava dedicar muito tempo aos oradores, ...para garantir a justiça de todas as formas possíveis. Como conseqüência, ele permaneceria julgando o mesmo caso por onze ou doze dias, mesmo que às vezes realizasse audiência à noite. (LXXII, 6,1)

A inscrição publicada por James Oliver foi a resposta a uma embaixada ateniense, encontrada em 1966 no pavimento da Ágora Romana. Nela encontramos as sentenças imperiais para oito apelações 
(1s.1-46), seguidas das decisões tomadas e de observações gerais (p. 47104). Esta parte final, ao contrário das apelações, tem um caráter mais geral e normativo, e é dirigida à cidade como um todo, sendo importante por representar justamente o momento em que o poder imperial se fazia presente junto aos seus súditos. Isso é relevante, pois é nela que o imperador trata dos custos da embaixada:

Para Agathocles filho de Agathocles pelos serviços diplomáticos que desempenhou em minha corte: a reivindicação deve ser paga. Para sua pátria e para o tribunal dos Areopagitas os depósitos pelas causas apeladas (...) devem ser reembolsados. (1s.47-52)

Podemos destacar, com isso, um elemento importante no funcionamento das cidades gregas: o envio da embaixada não foi uma iniciativa individual, mas de uma instituição jurídica, o Areópago. Agathocles, o embaixador responsável por levar os apelos à instância superior (o poder imperial), não estava cumprindo uma obrigação, como uma liturgia. Uma liturgia, observou Paul Veyne (1976, p. 185), era uma contribuição obrigatória para determinados membros da elite urbana, tida não como um imposto, mas como uma honra. Sendo obrigatória não teria porque ser ressarcida, e se isso aconteceu é porque havia o entendimento de que o embaixador prestava um serviço à comunidade, e que como tal podia ou não ter seus gastos cobertos pelos interessados.

$\mathrm{O}$ fato de as respostas às apelações apresentarem uma mesma estrutura tambémé esclarecedor: são iniciadas pelo nome dos envolvidos, seguidas pelo nome do tribunal do qual se estava apelando (se fosse o caso) e pela apresentação dos motivos e argumentos, terminando com a sentença imperial. Essa ordem indica que estava sendo seguido aí o procedimento chamado cognitio, o procedimento legal mais comum no Império, no qual todo o processo e todas as medidas ficavam nas mãos do juiz (Garnsey, 1981, p. 167). Isso implicava em uma grande concentração de poder, e não poderia ser de outra forma, uma vez que $o$ juiz no caso era a autoridade máxima em Roma.

Não podemos nos esquecer que, desde a reordenação jurídicopolítica promovida no início do Principado, estabeleceu-se uma relação bastante clara entre o direito local e o imperial: definido como costume, o direito local foi preservado na medida em que foi limitado à esfera do 
privado. O direito público é que se tornou objeto do direito romano, expresso na lei $^{3}$. Justamente essa esfera do direito vinha passando por uma importante transformação: o reinado de Marco Aurélio se situa em um processo de afirmação do poder imperial caracterizado pela maior amplitude e pelo caráter mais geral das decisões imperiais. Se até o imperador Adriano (117-138) uma decisão imperial legal tinha um caráter limitado, sendo uma resposta concreta a um problema específico, a partir daí passou a ter efeitos mais amplos. O Poder Imperial começava a se afirmar como únca fonte da lei, acabando com a distinção entre lex e ius (Grelle, 1993, p. 77; Palazzolo, 1986, p. 58). Assim, o que podemos ver é que as próprias cidades através de suas embaixadas forneciam a ocasião para a expansão da influência imperial. $O$ fato de as pessoas citadas serem todas membros da elite ateniense, o que pode ser depreendido quando observamos os casos em questão, reforça a idéia de que a maior parte das embaixadas se referia aos assuntos das classes dominantes.

Mais interessante ainda é o conteúdo dos casos analisados: quatro tratam de eleições - uma para o Areópago, outra para uma função sacerdotal ligada aos Mistérios de Elêusis, e duas para o Panhellenion. No caso destas últimas - para o Panhellenion - (1s.15-22), a intervenção imperial seria de se esperar. Afinal, fora Adriano o criador dessa instituição, na qual se encontravam representantes de todas as cidades gregas. Esse mesmo imperador já havia estabelecido os critérios para a escolha dos membros desse órgão, entre os quais uma idade mínima e a experiência na vida pública. O que se entendia aí como "cidades gregas" era uma referência cultural, e não étnica: daí cidades do Sul da Itália, como Nápoles, participarem (Lomas, 1995, p. 116). Marco Aurélio reforçava, assim, um efeito das ações de seu antecessor: o poder imperial era um elemento ativo na definição da identidade helênica. Isso podia significar, inclusive, determinar quem podia ou não participar do órgão que a representava, o que era ainda mais importante por ser a pedido dos próprios atenienses.

Tratando da eleição para o cargo sacerdotal, Marco ia ainda mais longe. Afinal, os sacerdócios eleusinos eram controlados por duas famílias, os Eumólpidas e os Ceryces, sob a supervisão da cidade. Em sua decisão, o imperador proibia que o acusado (um eumólpida) assumisse o sacerdócio, determinando a realização de uma nova eleição (1s.7-14). O próprio Marco só seria iniciado nos mistérios de Elêusis em 178 d.C. (Dião Cássio, 
LXXII, 31,3; Millar, 1992, p.450), portanto quatro anos após ter atendido a esta petição ateniense. É interessante observar que agia, assim, como alguém "externo" ao culto, um não-iniciado que a despeito disso era dotado de capacidade de intervenção. Apenas em um dos casos o imperador deixou de proferir uma decisão concreta: tratando da reivindicação de um candidato ao Areópago, Marco Aurélio determinou que seus representantes na Grécia, os Quintilii, deveriam decidir (1s. 2729). Mesmo sem tomar a decisão final, no entanto, foi ele quem apontou os juízes que deveriam ser obedecidos, mostrando o grau de sua intromissão nos assuntos da cidade.

Podemos observar, portanto, que a elite ateniense buscava o centro do Império para definir e esclarecer questões relativas à ocupação de espaços de poder. $\mathrm{O}$ imperador romano era convidado a ocupar um espaço decisivo no próprio arranjo institucional dessa elite, ou ao menos é o que esta inscrição sugere. O caso do Areópago é ainda mais interessante, pois permite observar uma mudança na orientação política imperial. Em uma passagem mais próxima do fim da inscrição, quando não está respondendo a nenhuma petição, Marco Aurélio redefiniu as regras para a participação nesta assembléia (ls.57-80). Observou, aí, que devido às dificuldades que os atenienses vinham encontrando para eleger cidadãos que cumprissem o requisito para esse fim, os critérios deveriam ser mais brandos: apenas o pai do candidato deveria ter sido livre, seu avô poderia ter sido um liberto. Abria, assim, caminho para que a cidade se beneficiasse politicamente das novas fortunas, contrariando uma medida que ele mesmo havia tomado em 169 (criando critérios mais rígidos para a eleição ao órgão).

Isso nos coloca em contato com uma questão de grande importância para a compreensão do funcionamento das cidades gregas. Construções, festivais, escolas e diversos outros aspectos da vida cívica dependiam da contribuição de membros das elites. $\mathrm{O}$ fato de, com a conquista romana, ter se verificado um processo de concentração fundiária e migração da população rural para as cidades, tornou estas ainda mais fragilizadas socialmente, ainda mais dependentes destas contribuições voluntárias (Woolf, 1994, p. 418). Isso permitiu, por sua vez, o acúmulo de prestígio e a ascensão política das elites municipais gregas aos postos mais altos do Império, inclusive ao Senado. Ou seja, a dominação romana beneficiou as elites gregas material e politicamente: como mostrou André 
Chastagnol (1992, p. 160), até o final do século II grande parte dos membros da Cúria em Roma seria de origem helenizada.

Este processo não impediu que essa mesma elite passasse por transformações no período imperial. A historiografia tem promovido um intenso debate a respeito da origem das fortunas aristocráticas, especialmente como uma reação à idéia de que o comércio seria uma atividade no máximo marginal, em contraste com o caráter agrário das fortunas de então (Garnsey e Saller, 1987, p. 45). O que se observou recentemente, no entanto, é que o comércio exercia um papel fundamental e complementar ao da agricultura no funcionamento do patrimônio da elite imperial, como um todo, sendo a principal fonte do dinheiro gasto na cidade com o evergetismo e o estilo de vida luxuoso (Wallace-Hadrill, 1991, p. 250). Isso dava um caráter muito mais dinâmico a essa elite, facilitando a transferência de riquezas e a ascensão social, o que acabava gerando problemas de natureza política.

Não é à toa que um dos casos julgados diga respeito a um pedido de cidadania ateniense (ls. 30-34: a decisão fica a cargo do Areópago), e que na questão do Areópago de que tratamos mais acima o imperador tenha reduzido justamente a exigência que impedia a ascensão dessa elite renovada. Mais do que assegurar a continuidade das classes dirigentes, o que se fazia assim era garantir o próprio funcionamento da cidade, mesmo que modificado. Podemos dizer, assim, que a relação centro imperial - Atenas possuía uma dimensão "produtiva", em que a ação estatal se adequava às dinâmicas locais ${ }^{4}$.

A participação na cidadania local era importante por definir direitos mas também deveres do cidadão. Por isso não é de estranhar que o pleiteante, cujo caso foi encaminhado ao Areópago, tivesse aliados e oponentes em seu pedido. Vale a pena observar, aliás, que membros dessa mesma elite buscavam, às vezes fugir destas obrigações: em sua primeira sentença Marco observou que todos aqueles que possuíam um sacerdócio voluntário (ou seja, que não foram eleitos para o cargo) deveriam continuar cumprindo suas obrigações e doando grãos à cidade (ls. 1-6).

Os casos mais complicados, no entanto, são os que envolvem problemas econômicos. O primeiro (ls. 23-26), trata de uma queixa contra os administradores de uma propriedade; o segundo, de testamentos adulterados que teriam afetado os interesses do herdeiro (ls.35-46). Nos 
dois casos, Marco era obrigado a contrariar os interesses econômicos de uma mesma pessoa, Herodes Ático. Ático era membro de uma poderosa família grega, famoso por sua imensa fortuna, membro da ordem senatorial, e havia sido professor de eloquiência do próprio Marco Aurélio (História Augusta, Vita Marci Antonini, II,3) e de Lúcio Vero, irmão adotivo de Marco e co-imperador até 169 (H.A., Verus, II,5) .

Na época da embaixada em questão, Ático havia se auto-exilado de Atenas, devido aos processos que a cidade movia contra ele. Protestava-se contra seu poder e seu domínio na cidade. Apesar de Marco ter ido contra os interesses de seu amigo, a inscrição foi encerrada com um pedido para que os atenienses se reconciliassem com ele, lembrando-os dos benefícios trazidos por ele para a cidade, especialmente para a cultura e a educação. Como observou, agora que todas as pendências estavam resolvidas, era o momento de todos os ressentimentos serem deixados de lado (1s.87-95).

Nada escapava, portanto, à ação do imperador. Melhor dizendo: nenhum assunto interno da cidade era considerado pelos cidadãos como estando fora da alçada imperial. Marco intervinha no funcionamento e na reprodução do corpo social, como vimos, e até mesmo em questões de política interna. Se era função do imperador intervir nestas questões, ao mesmo tempo, quando o fazia, este acabava contribuindo para a construção de uma determinada concepção que os outros tinham de seu poder.

Como a análise da inscrição mostra, o imperador, mesmo sendo um "estrangeiro" (no sentido de não-ateniense) e um não-iniciado, tinha sua importância para os assuntos cívicos reconhecida por aqueles que estavam diretamente envolvidos. É reconhecida nele, assim, a existência de uma autoridade que é válida mesmo para assuntos religiosos, e que é aplicada de maneira concreta, através de suas decisões e sentenças. Quando analisamos o governo de Marco como um todo, aliás, podemos ver que esse mesmo padrão se repete, e em escala muito maior (Oliver, 1970, p. 1).

A inscrição traz, ainda, a justificativa imperial para a tomada das decisões que divulga. $\mathrm{O}$ imperador afirmou ter como objetivo preservar a reputação de Atenas, para que a cidade mantivesse sua antiga dignidade (1s. 57-58). Afirmando tentar fazer com que a cidade permanecesse vivendo de acordo com a tradição, Marco arrogava para si um importante 
papel, definindo todo o enquadramento ideológico para suas ações. O fato de estes dois elementos (ação e justificativa teórica) virem lado a lado só ressalta a importância do pronunciamento imperial. É importante observar que, dessa forma, deixamos de lidar apenas com questões práticas, concretas. Passamos a lidar também com um "modelo", uma construęão ideológica do que seria o "bom imperador", baseada na idéia de que ele devia governar cuidando da justiça, da religião e da harmonia social.

Isso é ainda mais interessante quando pensamos na proliferação desses modelos a partir da fundação do Império (e dando continuidade a uma prática helenística). Tanto na capital quanto nas províncias, intelectuais desenvolviam concepções definindo os atributos do bom governante, justo e pio. Atuavam como conselheiros e propagandistas do monarca, simultaneamente (Hidalgo de La Vega, 1995, p. 22). O que nos interessa aqui é chamar a atenção para como a justificativa teórica de que falamos coincide com um determinado modelo que teve ampla divulgação nessa época, modelo este que podemos encontrar em alguns discursos de Dião Crisóstomo (especialmente em seus quatro Discursos sobre a Realeza). O famoso orador de origem helênica conhecera o apogeu de sua carreira política ainda no início do reinado de Trajano, por volta do ano 100. Segundo Hidalgo de la Vega, nessa ocasião teve a oportunidade de proferir uma série de discursos perante a corte, em alguns dos quais tratou do tema que nos interessa aqui. Associava, aí, a realeza terrena à realeza divina, fazendo de Zeus o modelo a ser copiado pelo imperador: é chamado "rei" por seu domínio e poder; "pai" por sua solicitude e gentileza; "protetor das cidades" por defender a lei, entre outras qualidades ( $1^{e}$ Discurso, 40). Resumindo, para o bom rei o cuidado com seus súditos era a essência de seu trabalho ( $3^{2}$ Discurso, 55 ).

É importante observar que este modelo estabelece um padrão ao qual se adequa a inscrição imperial. Há uma coincidência entre a ação de Marco Aurélio (ou talvez seja mais correto dizer: a maneira como ela é apresentada) e o ideal cultivado por Dião Crisóstomo. Essa coincidência é reforçada pelo julgamento que é feito deste imperador em sua biografia na História Augusta - por mais que essa obra reserve-lhe algumas críticas (Machado, 1998, p. 95) - e especialmente pelo julgamento presente na História Romana de Dião Cássio. Dizemos especialmente porque Cássio foi um quase contemporâneo deste imperador, tendo sido senador 
durante o reinado de seu filho. Trata-se de uma opinião praticamente contemporânea à inscrição.

Podemos dizer, portanto, que alguns dos critérios que presidiam a definição do bom imperador eram partilhados, no século II, por membros das elites cultas - em Roma ou no Oriente. Isso significa que, nas relações entre os imperadores romanos e as cidades gregas, além de uma dimensão prática, também entrava em jogo uma dimensão cognitiva. Esta associação não deixa de ser razoável: a dinastia dos Antoninos, aliás, pode ser tomada como um exemplo bastante produtivo. Não há dúvidas de que a partir do reinado de Adriano realizou-se uma crescente helenização do centro imperial, da corte e da própria maneira de se conceber e representar o poder imperial. Paul Zanker (1997, p. 256) chamou a atenção para o desenvolvimento de um "rosto da época" nas representações estatuárias do imperador, de sua família e das elites gregas nessa época, o que indicaria a existência de um "consenso difuso" em torno da imagem adequada ao "bom cidadão".

A existência deste "consenso difuso", de que fala Zanker, joga uma nova luz à inscrição de que estivemos tratando, permitindo enquadrála em um contexto intelectual mais amplo. Isso fica ainda mais claro quando pensamos em seu contexto de exposição: a Ágora romana, também conhecida como Ágora de César e Augusto. Apesar de uma certa decadência econômica, a cidade de Atenas, desde o início do Principado, gozou de um imenso prestígio intelectual e religioso. Apenas no século II d.C. é que voltou a se beneficiar da munificência privada (o Herodes Ático de que falamos acima está diretamente ligado a esse ressurgimento), ficando a cidade antes disso dependente das doações imperiais (Gros e Torelli, 1988, p. 383).

O espaço de que estamos tratando havia sido projetado por Júlio César em 47 a.C., como uma praça retangular voltada para o comércio - mesma época em que construía seu fórum em Roma -, mas só foi inaugurado por Augusto, entre 11 e 9 a.C. O valor do investimento feito, o luxo da decoração e a presença de estátuas de membros da família imperial ressaltavam o valor "representativo" e "dinástico" desta construção, seguindo-se essa tendência também nas construções imperiais por todo o Império, e especialmente na capital (Gros e Torelli, 1988, p. 384).

A Ágora romana ocupava, então, um espaço privilegiado na cidade, por sua função e por sua localização: associava-se à antiga Ágora 
(que também vinha passando por importantes transformações, com diversas obras), à qual era ligada por uma rua (Mavromataki, 1995, p. 66). A escolha do local para a exposição da inscrição de Marco Aurélio, assim, não deve ter sido acidental. Numa cidade consagrada pelos deuses e pela tradição, no pavimento de um espaço monumental e exaltativo da dominação romana, aí foi o local escolhido para a inscrição das decisões imperiais. $\mathrm{O}$ ato e a escolha são repletos de significados: inscrever é tornar ao mesmo tempo visível para a apreciação de todos e permanente uma ação que de outra forma permaneceria contingente. Neste local, ao alcance de todos os transeuntes, a inscrição - com sua justificativa podia ser lida em qualquer ocasião: enraizava a vista de todos a concepção do poder imperial que Marco Aurélio queria divulgar de si, legitimando sua posição distante, porém proeminente.

Ao se perguntar como observar, em diversas sociedades, os fatos da coesão social e da autoridade, Marcel Mauss advertiu que apenas o Estado não basta para garantir a existência de tais elementos (1981, p. 340). O que notamos aqui é que, apesar de o aparato estatal ser de grande importância - envolvendo tanto governadores e funcionários quanto a presença de forças armadas - existe uma outra dimensão que permite e acentua a aproximação entre as elites locais e o poder imperial: uma dimensão que podemos chamar de "cognitiva", ligada a uma maneira específica de apreender a realidade social e política. Assim, predominam nos contatos entre o imperador e a cidade de Atenas valores como civilidade, liberdade e ordem: o governante do império deve se comportar como o primeiro cidadão, aquele que irá preservar os direitos e as liberdades, garantindo o funcionamento ordenado daquela sociedade. $\mathrm{O}$ "consenso difuso" de que falou Zanker exerce, aí, um importante papel na legitimação mas também no funcionamento da ordem imperial.

Podemos observar, assim, dois fenômenos contemporâneos e complementares: a helenização do centro imperial e a romanização de Atenas (e das cidades gregas). A romanização, nesse caso, foi um processo mais sutil, mais claramente visível em sua dimensão política: as elites locais buscavamm o poder imperial para manter sua ordem em funcionamento, atribuindo-lhe um papel estruturante. Essa romanização, portanto, não foi um produto do uso da força bruta: deu-se respeitando alguns dos limites e interesses atenienses. Como vimos no início, no entanto, essa foi uma relação assimétrica: os imperadores aproveitaram esse 
movimento das elites para ampliar seu poder e sua importância para elas. Nesse sentido, podemos discordar da afirmação de Gellner, de que nos impérios antigos as comunidades locais prescindiam da estrutura mais ampla: com o passar dos séculos isso foi se tornando cada vez menos verdadeiro.

A helenização do centro imperial contribuiu para isso, tornandoo mais aceitável, desejável até, uma vez que conformado a um ideal partilhado pelas classes dirigentes locais e centrais. Passava a ser um poder capaz de se justificar utilizando as mesmas categorias valorizadas pelos seus súditos, especialmente por aqueles de extração social mais alta. Se isso é verdade, cabe ainda perguntar: até que ponto o Império Romano pode ser considerado o produto de um acordo entre as elites? Se as relações que estivemos analisando aqui se aplicam às cidades helenísticas, não é verdade que se apliquem ao Ocidente; como essa diversidade era administrada? A historiografia tem se debatido extensamente com estas questões, o que significa que a existência imperial não pode mais ser tomada como um fato evidente por si só. O que podemos observar é que o processo de integração se deu de maneira complexa e talvez até mesmo incompleta em alguns casos. A força foi o elemento fundamental nas conquistas do Império, mas sua manutenção exigiu o recurso a meios mais sofisticados: longe de ser um gigante inabalável ou estático, o "Império Romano" deve ser entendido como um conjunto de relações de poder, assentado em uma estrutura estatal, que porém foi construída em meio a estas mesmas relações.

\begin{abstract}
This paper seeks to explore the relationship between Roman Empire and Greek poleis in the $\mathrm{I}^{\text {th }}$ century. The imperial political power depended on an intricate web of relationship based on estate structure which were built together.
\end{abstract}

Key words: Roman Empire; Greek poleis; imperial power.

\title{
Notas
}

1. As demais obras clássicas utilizadas foram aquelas editadas pela Loeb Classical Library, Cambridge(Ma)/London: Harvard University Press/William Heinemann. 
2. Conferir a discussão feita por Goodman, 1997, especialmente o capítulo 13: "The extent of political unity". A natureza da dominação romana foi discutida de maneira extremamente pertinente por Greg Woolf (1993), que mostrou como "força", "dominação" e "consenso" foram habilmente impostos às regiões subjugadas.

3. Estamos seguindo aqui os argumentos de Mélèze Modrzjewski, 1993, p. 986. Para o que segue, cf. também Grelle, 1993 e Palazzolo, 1986.

4. David Nugent (1994) observou que no Peru, entre as décadas de 1930 e 1960, as relações entre a organização estatal e a região de Chachapoya, ao Norte do país, assumiu exatamente esse caráter, apesar de obviamente os resultados não terem sido os mesmos.

5. A proximidade entre Herodes Ático e o círculo imperial é perceptível até mesmo através da comparação dos retratos imperiais feitos nesta época, como mostraram Albertson, 1983 e Smith, 1998.

\section{Referências Bibliográficas}

ALBERTSON, Fred. A bust of Lucius Verus in the Ashmolean Museum, Oxford, and its Artist, American Journal of Archaeology, 87(2): 153-163, 1983.

CHASTAGNOL, André. Le Senat Romain a l'Époque Imperiale. Paris: Belles Lettres, 1992.

GARNSEY, Peter. El privilegio legal en el Imperio Romano. In: FINLEY, M.I. (org.). Estudios sobre Historia Antigua. Madrid: Akal, 1981, p. 157-183.

GARNSEY, Peter, SALLER, Richard. The Roman Empire: Economy, Society and Culture. Berkeley: University of California Press, 1987.

GELLNER, Ernest. Escala e Nação. In: Nacionalismo e Democracia. Brasília: UNB, 1981, p.43-59.

GOODMAN, Martin. The Roman World. 44 BC-AD 180. London: Routledge, 1997.

GRELLE, Francesco. La forma dell'Impero. In: Storia di Roma, T.III, v.1, Torino: Einaudi, 1993, p. 69-82.

GROS, Pierre, TORELLI, Mario. Storia dell'urbanistica - Il mondo romano. Bari: Laterza, 1988. 
HIDALGO DE LA VEGA, Maria José. El Intelectual, la Realeza y el Poder Político en el Imperio Romano. Salamanca: Ediciones Universidad de Salamanca, 1995.

JONES, A.H.M.. I Greci nell'Impero romano. In: La Economia Romana. Bari: Laterza, 1984, p.119-148.

LOMAS, Kathryn. Urban elites and cultural definition: Romanization in southern Italy. In: CORNELL, Tim, LOMAS, K. (eds.). Urban Society in Roman Italy. New York: Saint Martin's Press, 1995, p.107120.

MACHADO, Carlos Augusto R. Imperadores imaginários: política e biografia na História Augusta, São Paulo: Dissertação de mestrado apresentada à USP, 1998.

MAUSS, Marcel. A coesão social nas sociedades polissegmentares. In: Idem, Ensaios de Sociologia, São Paulo: Perspectiva, 1981, p.339350 .

MAVROMATAKI, Maria. Athens: Between Legend and Myth. Athens: Haitalis, 1995.

MÉLÈZE-MODRZEJWSKI, Joseph. Diritto romano e diritti locali. In: Storia di Roma, T.III, v.2, Torino: Einaudi, 1993, p.985-1009.

MILLAR, Fergus. El imperio romano y sus pueblos limítrofes. Madrid: Siglo XXI, 1976.

. Empire and City, Augustus to Julian: obligations excuses and status. Journal of Roman Studies, 73: 76-96, 1983.

. State and Subject: The Impact of Monarchy. In: MILLAR, Fergus e SEGAL, Eric (eds.). Caesar Augustus: Seven Aspects, Oxford: Oxford University Press, 1984, p. 37-60.

. The Emperor in the Roman World. Ithaca: Cornell University Press, 1992.

NUGENT, David. Building the State, Making the Nation: the bases and limits of State centralization in modern Peru. American Anthropologist, 96(2): 333-370, 1994.

OLIVER, James H.. Marcus Aurelius: aspects of civic and cultural policy in the East. Athens: American School of Classical Studies/ Hesperia: Supplement XIII, 1970. 
PALAZZOLO, Nicola. Crisi istituzionale e sistema delle fonti daí Severi a Costantino. In: Società Romana e Impero Tardoantico. V.1, Bari: Laterza, 1986, p.57-70.

SMITH, R.R.R. Cultural choice and political identity in honorific portrait statues in the Greek east in the second century A.D. Journal of Roman Studies, 88: 56-93, 1998.

VERNANT, Jean-Pierre. Mito e Religião na Grécia Antiga. Campinas: Papirus, 1992.

VEYNE, Paul. Le Pain et le Cirque. Paris: Seuil, 1976.

WALLACE-HADRILL, Andrew. Elites and trade in the Roman Town, in: RICH, J. e WALLACE-HADRILL, A. (eds.). City and Country in the Ancient World. London: Routledge, 1991, p.241-272.

WOOLF, Greg. Roman Peace. In: RICH, John e SHIPLEY, Graham (eds.), War and Society in the Roman World. London: Routledge, 1993, p. 171-194.

Town, country and imperialism in Roman Greece. Journal of Roman Archaeology, 7, p.417-420, 1994.

ZANKER, Paul. La Maschera di Socrate: l'immagine dell'intellettuale nell'arte antica. Torino: Einaudi, 1997. 